\title{
Conselhos gestores de políticas públicas: aspectos teóricos sobre o potencial de controle social democrático e eficiente
}

\author{
Management councils of public policies: theoretical aspects on the potential of a \\ democratic and effective social control
}

Eduardo Granha Magalhães Gomes ${ }^{1}$
Ministério do Planejamento, Brasília-DF, Brasil

\section{Resumo}

A proliferação dos conselhos gestores de políticas públicas enseja a avaliação do seu potencial para aprofundar o conteúdo democrático da gestão pública e aumentar a eficiência das políticas públicas por meio do controle social. Com esse intuito, este ensaio teórico contrapõe as dimensões representativa e deliberativa de democracia com as críticas ao sistema representativo e ao método democrático de agregação de preferências, e analisa, ainda, a propensão à responsabilização do governo no tocante às sinalizações de políticas processadas pelo conselho. A argumentação apoia-se em estudos internacionais importantes sobre os modelos representativo e deliberativo de democracia em diálogo com referências nacionais sobre o tema controle social. Conclui-se que os conselhos possuem potencial para promover o aprofundamento democrático na gestão das políticas públicas, particularmente pelo fortalecimento de condições que viabilizam um processo deliberativo igualitário. No entanto, tal potencial é estreitamente relacionado ao âmbito geográfico e à abrangência setorial: instâncias participativas municipais e de escopo singular possuem maior potencial democrático do que instâncias nacionais de amplitude temática mais abrangente. Em qualquer caso, a realização desse potencial condiciona-se a arranjos institucionais que viabilizem os incentivos para assegurar a legitimidade tanto dos representantes da sociedade civil como do governo, o processo deliberativo igualitário e a disponibilidade dos instrumentos de enforcement das decisões do conselho. Este artigo almeja contribuir para o desenvolvimento do ferramental analítico necessário ao estudo dos conselhos e à construção de arranjos institucionais efetivos dessas instâncias vis-à-vis seus objetivos democráticos e de eficiência.

Palavras-chave: Conselhos Gestores de Políticas Públicas. Controle Social. Accountability. Responsabilização.

\section{Abstract}

The proliferation of management councils of public policies gives rise to assessing their potential to deepen the democratic contents of the public management and increase the effectiveness of public policies through social control. With this purpose, this theoretical essay opposes the representative and deliberative dimensions in democracy to criticism against the representative system and the democratic method of aggregating preferences, and it also analyzes the propensity for government accountability as for the signalization of policies processed by the council. Argumentation relies on significant international studies about the models of representative and deliberative democracy and on dialogue with Brazilian studies addressing the theme social control. It is concluded that the councils have potential to foster a democratic deepening in management of public policies, particularly by strengthening conditions that enable an

Artigo recebido em 19 de maio de 2014 e aceito para publicação em 24 de fevereiro de 2015.

\section{DOI: http://dx.doi.org/10.1590/1679-395123196}

1 Doutor e Mestre em Administração Pública e Governo pela Fundação Getulio Vargas / EAESP; Administrador e Engenheiro Metalúrgico pela Universidade Federal de Minas Gerais; Especialista em Políticas Públicas e Gestão Governamental pela Escola Nacional de Administração Pública. Endereço: SQN 214, Bloco F - Apto 505 - Asa Norte, CEP 70873-060, Brasília - DF, Brasil. Email: eduardo.granha@gmail.com 
egalitarian decision-making process. Nevertheless, such potential is closely related to the geographical domain and the sectoral scope: municipal participatory bodies with an only scope have greater democratic potential than national bodies having a broader range of themes. In any case, making this potential a reality is conditioned to institutional arrangements that enable incentives to ensure the legitimacy of representatives both of the civil society and the government, the egalitarian decision-making process, and the availability of tools to enforce council's decisions. This article hopes to contribute to developing the analytical tools needed to study the councils and build effective institutional arrangements of these bodies vis-à-vis their democratic and effectiveness goals.

Keywords: Management Councils of Public Policies. Social Control. Accountability.

\section{Introdução}

A partir da Constituição Federal de 1988, os conselhos gestores tornaram-se instituições importantes no âmbito das políticas públicas. Decorrentes, sobretudo, dos princípios constitucionais que prescrevem a participação da sociedade na condução das políticas públicas, das legislações regulamentadoras que, invariavelmente, condicionam o repasse de recursos federais à sua existência e do processo de descentralização, eles se disseminaram pelos municípios e estados brasileiros. No entanto, a expansão quantitativa dos conselhos gestores não significou necessariamente o sucesso dessa nova institucionalidade na superação dos desafios a ela interpostos. Esse aspecto qualitativo é, realmente, mais desalentador, como revelam relatos de experiências práticas: deficiências quanto à representatividade dos conselheiros, quanto à capacidade de deliberar, impor suas decisões e controlar as ações do governo são frequentemente apontadas na literatura (CARVALHO, 1998; TEIXEIRA, 2000).

Essas dificuldades, constatadas no cotidiano dos conselhos no Brasil, suscitam, então, alguns questionamentos relativos à viabilidade ou ao potencial desse formato institucional para o alcance dos objetivos a que se propõe; fundamentalmente, quanto ao objetivo de constituir instância de controle social democrático e eficiente sobre as políticas públicas. Este estudo busca, assim, proceder a um levantamento teórico das condições inspiradoras desse movimento conselhista, abrangendo tanto os condicionantes políticos, notadamente as críticas ao sistema democrático representativo e a defesa de uma prática deliberativa de democracia, como os condicionantes socioeconômicos associados aos movimentos de boa governança que prescrevem a participação ativa da sociedade, para o aumento da eficiência das políticas públicas. Tais condições são confrontadas com uma definição mínima dos conselhos, procurando verificar o potencial desse formato para superar as críticas ao sistema representativo, realizar as possibilidades da democracia deliberativa e exercer controle social sobre o governo, as políticas públicas e seus resultados.

Para isso, estabelecemos uma definição mínima de conselho gestor de política pública como um colegiado institucionalizado, municipal, composto por pequeno número de representantes do governo e da sociedade civil, estes designados democraticamente, que é responsável pela gestão de determinada política pública ${ }^{2}$. Por gestão definimos desde a formulação e o planejamento da política pública, o acompanhamento de sua implantação, a avaliação de seus resultados e a retroalimentação do sistema de gestão, incluindo o estabelecimento de ações corretivas e preventivas aos comportamentos e/ou eventos desviantes.

Com essa definição é possível identificar, relativos à questão democrática, dois distintos pontos de análise: o conselho encerra tanto aspectos relacionados à democracia representativa, uma vez que os conselheiros são representantes, e à democracia deliberativa, dado o caráter plural e colegiado da gestão.

\footnotetext{
${ }^{2}$ Embora haja conselhos gestores em diversos níveis, a delimitação do objeto ao âmbito municipal neste estudo visa a aproximar ao máximo o conselho dos representados.
} 


\section{Os conselhos e as críticas ao sistema democrático representativo}

Entre os modelos democráticos, a democracia representativa tornou-se aquele factível nas sociedades contemporâneas, devido, fundamentalmente, às justificativas de ordem demográfica e de complexificação do escopo, normalmente em contraponto à perspectiva ensejada pela democracia direta. O inevitável instituto da representação, no entanto, não é desprovido de problemas.

Przeworski, Stokes e Manin (1999, p. 2) utilizam a sumária definição de Pitkin (1967) de representação: "Agir no melhor interesse do público". Essa definição suscita a primeira questão: é possível pensar no interesse do representado segundo seu próprio ponto de vista, mas, também, segundo o ponto de vista do representante. A possível diferença entre essas duas visões decorre, fundamentalmente, do acesso às informações e de processos cognitivos, além de questões funcionais relativas à própria divisão de trabalho que naturalmente existe entre representantes e representados. Essa diferença de visão, no entanto, torna-se um sério desafio à representação democrática, considerando aquela definição.

Outras considerações de Przeworski, Stokes e Manin (1999, p. 5-8) referem-se à distinção entre representação, "responsiveness" e "accountability". A representação é uma relação estabelecida entre interesses e resultados, enquanto podemos afirmar que um governo é responsivo quando implanta políticas vinculadas às sinalizações emitidas pelos eleitores. Esse governo responsivo, entretanto, pode não ser representativo se os resultados obtidos pelas políticas escolhidas não convergirem para os interesses dos representados. Ou seja, a correspondência entre representação e responsividade somente ocorreria se o eleitor tivesse as informações necessárias para escolher a política que concretizasse seus interesses, processasse corretamente essas informações e se o governo fosse competente para implantá-las. Certamente, algumas dessas condições podem não estar presentes, permitindo uma dissonância entre a representação e a responsividade.

Outra relação que se estabelece no sistema representativo democrático refere-se à possibilidade de sanção a que está submetido o representante. As eleições periódicas, por exemplo, são vistas como o mecanismo que permite ao cidadão manter ou reconduzir ao cargo os bons representantes e destituir os ruins. Ser "accountable" é, portanto, ser passível de uma punição caso os resultados, vistos retrospectivamente, não sejam satisfatórios, ou de uma recondução ao cargo, em caso contrário. "Accountability" é, assim, uma relação entre resultados e sanções. No entanto, assim como no caso do governo responsivo, a rigor, não há necessidade de ser "accountable" para ser representativo. Como coloca Pitkin (1967), citado por Przeworski, Stokes e Manin (1999, p. 165, tradução nossa), "reeleição não é uma boa prova de que ele é um governo representativo; prova, no máximo, que os eleitores pensam assim". Mais uma vez, as questões da disponibilidade da informação e da capacidade cognitiva do receptor da informação tornam-se fundamentais; além da existência dos necessários mecanismos de sanção.

Se não bastassem esses problemas de divergentes pontos de vista, a segunda questão envolvida na representação se refere à eventual dissonância entre os interesses do representante e dos representados. Przeworski, Stokes e Manin (1999, p. 3) enumeram quatro razões genéricas que poderiam levar os representantes a agir segundo o interesse dos representados:

1. Os representantes têm espírito público e permanecem assim durante o mandato;

2. Ainda que os candidatos a representantes tenham interesses, motivações e competências diferentes, os cidadãos usarão seu voto para selecionar efetivamente aqueles cujos interesses coincidem com os dos eleitores ou aqueles que são e permanecerão devotos ao serviço público enquanto em exercício;

3. Ainda que algum representante queira perseguir interesses diferentes do interesse público, os cidadãos utilizam seus votos efetivamente para ameaçar e destituir o representante;

4. A separação de poderes no governo, que permite os "checks and balances", conduz a agir no melhor interesse público. 
As duas primeiras razões são, a princípio, realizáveis, mas notadamente difíceis de ocorrer. A primeira encontra seu limite na atração que o cargo de representante pode exercer sobre os cidadãos e que, a rigor, não é pequena. Como lembra Lane (1979), citado por PRZEWORSKI (1994, p. 45), "o principal problema do poder político é que ele gera ganhos crescentes de escala", o que torna o cargo extremamente atraente para muitos, não somente para aqueles de espírito público. A segunda razão seria uma forma razoável de garantir uma boa representação, desde que os eleitores estivessem com as informações verdadeiras sobre os candidatos e não sofressem qualquer tipo de manipulação. Essa condição também recai sobre os problemas de informação e de cognição mencionados.

A terceira razão é mais factível, porém, imperfeita, como já discutido ao tratar de "accountability", além de não tratar do período entre eleições. Por fim, a quarta razão, inspirada fundamentalmente em Montesquieu e adotada em diversos países democráticos, como o Brasil e os EUA, ilude-se com uma divisão de poderes fortemente delimitada e precisamente equilibrada. A realidade revela uma fronteira fluida entre os poderes, em que a troca de atribuições entre legislativo e executivo é comum, em que ocorre a politização de uma burocracia concebida originalmente como mera executora das leis e onde há tentativas constantes de cooptação de um poder pelo outro, valendo-se dos recursos distribuídos de forma desequilibrada.

Finalmente, essa questão da divergência de interesses, entre representantes e representados, torna-se ainda mais complexa devido à possibilidade do agravamento deliberado da assimetria de informações entre as partes. PRZEWORSKI (1998, p. 45) lembra que a relação estabelecida entre eleitores e políticos é uma relação do tipo "agente-principal", onde os "agentes" detêm informações e conhecimentos necessários à consecução das atividades sob sua responsabilidade; informações que os eleitores ("principals") não possuem. No entanto, adicionalmente aos problemas presentes em uma relação "agente-principal" mais prosaica, como a que ocorre entre proprietários de veículos e mecânicos, a relação entre os políticos e os representados apresenta uma diferença fundamental: os políticos eleitos, enquanto legisladores, têm a prerrogativa de definir o que os "principals" devem saber e podem fazer, além de coagi-los a fazer (PRZEWORSKI, STOKES e MANIN, 1999, p. 24).

Assim, ainda que a democracia representativa tenha se tornado inevitável nas sociedades contemporâneas, o instituto da representação pode, de fato, impingir uma série de obstáculos à soberania popular, decorrentes, sobretudo, de assimetria de informações, deliberada ou não, entre representantes e representados, de insuficiências de capacidade cognitiva dos atores e da imperfeição dos instrumentos de sanção destinados a controlar a relação de representação (PRZEWORSKI, STOKES e MANIN, 1999)³.

Essas críticas e considerações, associadas ao fraco desempenho social, político e econômico de vários regimes democráticos, fortalecem a defesa de modelos democráticos alternativos, como a democracia direta e outras formas de envolvimento da sociedade, que visam ao aprofundamento do conteúdo democrático e à ampliação, além do político, dos âmbitos sob deliberação popular. Os conselhos gestores, por exemplo, com o envolvimento direto da sociedade civil na gestão das políticas públicas, representam uma resposta ou uma alternativa a esse sistema representativo clássico.

No entanto, também devido a questões de ordem demográfica, a participação da sociedade civil, nos conselhos gestores, também se faz por meio de representantes. Dessa forma, cabe perguntar em que medida o modelo de democracia representativa de designação e controle dos conselheiros da sociedade civil

\footnotetext{
${ }^{3}$ É importante, no entanto, lembrar Urbinati (1999, p. 5, 12, 36), em sua defesa do sistema representativo. Ela afirma que é a própria representação que abre espaço para o processo deliberativo, e elenca três razões: a imposição de um distanciamento temporal entre a exposição ao discurso e a tomada de decisão, o que favoreceria a reflexão individual sobre as escolhas possíveis; a viabilização da especialização do escopo da sociedade civil em direção ao controle, deixando as funções de tomada de decisão e de gestão para o governo; e, finalmente, pelo fato de que o representante não deve reproduzir estritamente a categoria representada, ou ao menos seus déficits e problemas. Ao contrário, deve transcender sua condição de classe e a causa representada, agregando valor a ela em um processo dialético com as demais posições.
} 
enfrenta e supera os problemas (ou "déficits") de representação usualmente discutidos quanto às instituições representativas clássicas, como o parlamento.

Inicialmente, essa discussão envolve, no âmbito dos conselhos, um componente não abordado anteriormente: a não universalidade do sufrágio para escolha desses representantes, legitimidade que é garantida no sistema eleitoral tradicional. Isto é, mesmo que por algumas razões as eleições também sejam frequentemente questionadas quanto à sua legitimidade devido, por exemplo, à manipulação da mídia, elas têm um alcance universal, seguem regras institucionais consolidadas, inclusive tornando o voto compulsório, e são submetidas a controles, como da própria mídia, cuja severidade depende do nível de governo a que se referem. Ou seja, as instituições eleitorais nacionais e seus desdobramentos estaduais e municipais procuram garantir uma disputa democrática em torno dos poderes executivo e legislativo.

No entanto, no âmbito dos conselhos, essas instituições não chegam. As regras institucionais, que devem zelar pela extensão do sufrágio, pelo "sistema eleitoral" e, enfim, pela representatividade dos conselheiros, são locais; cabe a esse nível de governo, potencial e relativamente sob menor controle institucional que os demais, defini-las, institucionalizá-las e aplicá-las. Daí decorrem os questionamentos quanto à legitimidade democrática do processo de escolha dos conselheiros, representantes que serão corresponsáveis pela gestão de determinada política pública para todo o município. Isto é, colocam-se, a rigor, duas questões: quão democrático é o processo de definição das instituições da sociedade civil que se farão presentes nos conselhos e quão democrático é o processo de escolha dos representantes dessas instituições - sindicatos, associações - cujas regras são definidas internamente em seus regimentos.

Cabe ressaltar, por outro lado, que, do ponto de vista normativo, não é intenção dos conselhos alcançar uma representação similar, por exemplo, à Câmara de Vereadores, mas, sim, representações de amplitude temática ou territorial, decorrentes principalmente de participação cidadã voluntária, de onde emana outro tipo de legitimidade. Esse caráter voluntário, dados os custos envolvidos na participação, pode inclusive significar a manifestação de uma variável importante não captada pelo sistema eleitoral tradicional, em que é atribuído o mesmo peso a todos os atores: a intensidade das preferências sobre determinada política. Assim, alcançar um equilíbrio entre a representação parlamentar e as deliberações nos conselhos, entre os eleitores compulsórios e suas escolhas de políticas e os cidadãos participantes ativos e suas escolhas de políticas, torna-se de fundamental importância na discussão dos conselhos. Os conselhos municipais enfrentam, portanto, esta situação: uma limitada representatividade, ao menos quantitativa, se comparada às instituições cujos representantes são eleitos pelo sufrágio universal, atenuada se considerarmos o caráter voluntário da participação.

Entretanto, além da legitimidade eleitoral dos conselheiros, há outras questões que envolvem a relação de representação entre conselheiro e representado. Na discussão sobre representação, responsividade e "accountability" foi abordada a existência de pontos de vista diferentes entre representantes e representados, decorrentes da assimetria de informação e de insuficiências cognitivas, ambas inerentes às desigualdades sociais, naturais à divisão de trabalho presente na relação e/ou ainda agravadas por um comportamento autointeressado do representante. Essas deficiências, associadas à inexistência de mecanismos de responsabilização dos comportamentos desviantes, seriam as causas fundamentais dos déficits de representação.

Tais dificuldades de informação assimétrica, capacidade cognitiva e de responsabilização são facilmente imaginadas quando tratamos de uma distante e especializada representação parlamentar. No entanto, essas considerações podem ser amenizadas na relação de representação que ocorre entre conselheiros municipais gestores de políticas públicas e representados, uma vez que, segundo Gomes (2003, p. 48-49):

1. Os papéis dos conselheiros e dos representados não se enquadram em uma perspectiva de divisão de trabalho, ou seja, o representante não se especializa em "ser conselheiro" nem assume essa profissão, ao contrário de um parlamentar. Assim, não há justificativas naturais para a existência de assimetria de informações e diferenças de capacidade de processamento 
delas;

2. A menor atratividade do cargo de conselheiro, dado seu caráter não remunerado e os custos da participação, e em que pese a perspectiva de poder que o cargo enseja, é um fator que contribui para a redução do universo de candidatos, o que reduziria a probabilidade de comportamentos autointeressados;

3. A duração geralmente mais curta dos mandatos dos conselheiros gera uma expectativa de responsabilização mais frequente, o que pode induzir a um comportamento mais responsivo;

4. O caráter municipal do âmbito de representação, ressalvada a existência de municípios de grande porte, favorece, também, uma maior proximidade entre representado e conselheiro, de modo que a captação de preferências e o "feedback" relacionado às políticas públicas escolhidas pode ser mais direto e mais frequente;

5. A inexistência de intermediação, como, por exemplo, da mídia, também dificulta ações deliberadas do representante no sentido de agravar a assimetria de informações;

6. A participação e o envolvimento voluntário dos representados, nas instâncias de escolha de seus conselheiros, permitem inferir uma maior propensão ao exercício de uma participação também mais ativa e interessada no controle futuro das ações do conselheiro, quando comparada ao acompanhamento de uma distante representação parlamentar;

7. O caráter setorial ou temático do conselho reduz e especializa o escopo em discussão, permitindo um acompanhamento direcionado, em contraposição a uma representação parlamentar em que a complexidade e a diversidade dos assuntos tornam mais difícil e difuso um controle sobre o desempenho do representante;

8. O âmbito local torna mais palpável a relação entre política pública e resultados, permitindo aos representados "sentir na pele" as consequências dos atos dos conselheiros e responsabilizá-los de forma pertinente, inclusive subsidiando com informações o ciclo de gestão da política pública.

Certamente, tais atenuantes são potenciais e não garantias. Sua realização dependerá, entre outros fatores, do arranjo institucional que governa a relação de representação.

Portanto, potencialmente, a questão da representação democrática dos conselhos municipais gestores de políticas públicas, ao menos quanto à relação que se estabelece entre os conselheiros da sociedade civil e a própria sociedade, abrange, por um lado, críticas quanto à "pequena" extensão do sufrágio e quanto à sua legitimidade - sujeita aos critérios democráticos de designação legal das instituições representadas e da lógica democrática interna de cada instituição para a escolha de seus representantes; por outro lado, perspectivas de uma melhor representação dos interesses daqueles envolvidos no processo. Na seção a seguir, discutimos a relação que se estabelece entre os conselheiros e o governo.

\section{Os conselhos e a democracia deliberativa}

Além das críticas ao sistema democrático representativo, também pode ser depreendido do movimento conselhista o descontentamento com uma visão minimalista de democracia, presente na teoria democrática contemporânea, na qual ela é reduzida a um "procedimento de eleger governantes". Segundo essa visão, a democracia é desprovida de valores substantivos de igualdade política, soberania popular ou alcance do bem comum (PRZEWORSKI, 1994; DAHL, 1989, p. 25-26; 1997, p. 36). Fruto do desencanto diante do 
desempenho nitidamente insatisfatório, em termos econômicos e sociais, dos regimes democráticos vigentes, essa visão procedimental justifica o esvaziamento do conteúdo democrático rousseauniano negando a existência de um "único" bem comum a ser alcançado e a possibilidade da democracia para ele convergir. Isto é, devido à estruturação social que envolve interesses conflitantes e à impossibilidade prática de uma ampla concertação de interesses que levasse a um caminho único, torna-se bastante improvável a existência de um bem comum ou uma "vontade geral rousseauniana" nas sociedades capitalistas contemporâneas; de modo que os resultados da prática democrática não estariam dados de antemão sendo, ao contrário, incertos (PRZEWORSKI, 1994, p. 25).

De modo complementar à complexidade da estrutura social contemporânea, também o procedimento democrático clássico, baseado na simples agregação de decisões individuais, impõe novas limitações à realização dos ideais de igualdade política e soberania popular. Como enumera Dahl (1989, p.70), para concretizar tais ideais seria necessário que o método democrático satisfizesse as seguintes condições:

1. O voto de cada eleitor fosse uma manifestação autônoma de preferência entre as alternativas apresentadas;

2. Cada manifestação tivesse o mesmo peso;

3. A alternativa mais votada fosse declarada a vencedora;

4. Qualquer membro que considerasse uma alternativa qualquer preferível às alternativas disponíveis para votação pudesse inseri-la entre as apresentadas à votação;

5. Todos os indivíduos possuíssem informações idênticas sobre as alternativas;

6. Aas alternativas vencedoras (líderes ou políticas) substituíssem as alternativas perdedoras;

7. As ordens dos servidores públicos eleitos fossem executadas;

8. No interstício eleitoral, todas as decisões tomadas fossem decorrentes ou executivas das decisões tomadas na fase da eleição; ou que as novas decisões tomadas também fossem determinadas pelas sete condições precedentes, operando, contudo, sob circunstâncias institucionais diferentes.

As condições 1 a 3 e 6 são, a rigor, possíveis e constatadas nos sistemas democráticos conhecidos, ainda que, para isso, consideremos os votos brancos, nulos e abstenções como manifestações de preferência e desconsideremos a possibilidade de manipulação das preferências antes das eleições, preservando a autonomia do eleitor. Quanto à condição 6, a imperatividade das políticas escolhidas, a possibilidade de seu atendimento nos sistemas conhecidos depende de uma atenuante: essas alternativas vencedoras serem apenas macro políticas orientadoras, de conteúdo genérico, e não mais que isso.

As condições 4 e 5 são, inegavelmente, mais difíceis de constatar e, a meu ver, impossíveis em escalas maiores que um pequeno colegiado de escopo reduzido. A sétima condição, em alguma medida similar à sexta condição, remete às concepções idealizadas de burocracia, fiel cumpridora das ordens dos políticos, e do político, fiel representante dos interesses dos eleitores. Além disso, as condições enumeradas não dão conta de questões relativas às diferenças de intensidade das preferências que os diversos atores políticos possam legitimamente ter, o que reduz a conveniência da segunda condição, isto é, da condição que prescreve "uma cabeça, um voto".

Enfim, nas sociedades complexas não haveria condições razoáveis para esperar a realização dos ideais rousseaunianos pelo método democrático, uma vez que o próprio procedimento democrático não é igualitário e não permite uma real expressão da soberania popular.

Considerando esses argumentos, é possível inferir que haveria somente duas formas de "democratizar a democracia": melhorando o método e/ou reduzindo a complexidade da sociedade. O que tento argumentar, 
aqui, é que os conselhos municipais gestores de políticas públicas, devido ao seu âmbito local, ao seu caráter setorial e, fundamentalmente, ao seu caráter deliberativo, são instâncias de tomada de decisão democrática em que, dentro desses limites, ambas as possibilidades podem se realizar em grau considerável.

Essa perspectiva torna-se possível ao considerar que há duas concepções diferentes de democracia, em relação à forma de tomada de decisão coletiva. A concepção mais tradicional consiste na decisão tomada a partir de um processo de simples agregação de preferências individuais, preestabelecidas e para as quais se atribui o mesmo peso, tendo na regra da maioria um de seus pilares. Como exemplo emblemático, cabe lembrar a concepção rousseauniana de decisão coletiva: uma espécie de "agregação pura" que estabelece que os indivíduos devem formar suas preferências em total isolamento, com o objetivo de garantir sua imunidade contra os riscos de ser corrompidos pela eloquência e demagogia (ELSTER, 1998, p. 6).

No entanto, essa concepção de tomada de decisão coletiva não é única. Como contraponto à democracia agregativa há a democracia deliberativa, segundo a qual uma decisão é coletiva apenas quando emerge de arranjos de escolha coletiva que estabelecem condições de argumentação pública e livre entre iguais, que são governados pelas decisões (COHEN, 1998, p.186). Essencialmente, o que emerge nessa concepção é a possibilidade da democracia promover não apenas a agregação de preferências, mas, também, sua transformação por meio da discussão pública (ELSTER, 1998, p. 1) ou, ao menos, uma concertação com as demais preferências visando à tomada de decisão coletiva (COHEN, 1998, p. 199).

Tal perspectiva, que abre novas possibilidades para a questão democrática, tem como marco na teoria democrática o conceito habermasiano de esfera pública, que Avritzer (1999, p. 29-30) define como o espaço no qual

[...] os indivíduos interagem uns com os outros, debatem as decisões tomadas pela autoridade política, debatem o conteúdo moral das diferentes relações existentes no nível da sociedade e apresentam demandas em relação ao Estado... Os indivíduos no interior de uma esfera pública democrática discutem e deliberam sobre questões políticas, adotam estratégias para tornar a autoridade política sensível às suas discussões e deliberações.

Ou, como coloca Gohn (2001, p. 36),

[...] uma esfera que comporta a interação entre grupos organizados da sociedade, originários das mais diversas entidades, organizações, associações, movimentos sociais, etc. A natureza dessa esfera é essencialmente política argumentativa. É um espaço para o debate, face a face, dos problemas coletivos da sociedade, diferenciado do debate no espaço estatal propriamente dito.

Nele, prevalece a autoridade do melhor argumento.

Ou seja, na esfera pública, é isso que incentiva Avritzer (1999, p. 30) a considerar tal conceito a renovação mais importante da teoria democrática da segunda metade do século XX, vislumbra-se uma alternativa para superar as críticas e justificações que levaram ao "esvaziamento" do conceito de democracia e à consequente formulação da teoria procedimental, quais sejam, a impossibilidade de pensar a existência de um bem comum e a inviabilidade de uma concertação de interesses em uma sociedade complexa.

O ponto onde se almeja chegar aqui é que os conselhos deliberativos gestores de políticas, embora institucionalizados, estatais e menos autônomos que a esfera pública, podem usufruir de algumas das prerrogativas desse "sistema". Sua composição colegiada, envolvendo representantes do governo e da

\footnotetext{
${ }^{4}$ Ressalva-se, apenas, que o conceito original, o conceito habermasiano, preserva a autonomia da esfera pública e a informalidade do processo de formação de opinião. A transformação da "vontade política" construída nesses espaços em políticas públicas concretas
} 
sociedade civil, permite inferir que as decisões também são tomadas após a discussão de ideias entre indivíduos investidos do mesmo grau de autoridade, potencialmente onde prevalece o melhor argumento. E isso implica, e aqui temos um pressuposto a ser confirmado, que esse formato de instância democrática gera, de fato, decisões mais eficientes e mais democráticas, quando comparadas àquelas resultantes de um processo de simples agregação de preferências como uma votação.

A sustentação do pressuposto mencionado pode ser feita enumerando algumas características de um processo de argumentação pública e livre entre iguais para a tomada de decisão. Ou seja, podemos sugerir que a decisão por meio da argumentação é melhor porque (ELSTER, 1998, p. 11; GAMBETTA, 1998, p. 22; FEARON, 1998, p. 45-55; MARCH e OLSEN, 1989, p. 121):

1. Revela informações que não são públicas, distribuindo melhor as informações;

2. Diminui ou supera o impacto da "bounded rationality", propiciando inclusive mais criatividade nas soluções;

3. Reduz a prevalência das preferências dos atores que possuem "endowments" (recursos, capacidades, informação, autoridade) iniciais superiores;

4. Desestimula comportamentos autointeressados devido à exigência das justificações ocorrerem em público, o que torna o interesse público a única justificativa aceitável;

5. Desestimula dissimulações, uma vez que o discurso em prol do bem comum induz a alguma necessidade de consistência nos atos privativos, devido à necessidade de lidar com a dissonância cognitiva que discurso e atos divergentes podem trazer;

6. Legitima a escolha feita, uma vez que alcança consensos maiores e reforça o compromisso com sua implantação e suas consequências. Os participantes se veem na decisão;

7. É desejável per se, pois melhora a qualidade intelectual e moral dos participantes, disseminando princípios de "public life", além de propiciar certas habilidades e/ou virtudes, como eloquência, retórica, empatia, cortesia, imaginação, raciocínio, preparação;

8. Alcança decisões mais eficientes, uma vez que são tomadas a partir de argumentação racional justificada com informações e submetidas a múltiplas visões.

Tendo em vista essas características, é possível sugerir que as condições enumeradas por Dahl (1989) como necessárias a um procedimento de fato democrático, principalmente aquelas que foram apontadas como improváveis em um processo de agregação de preferências, podem ser substancialmente atendidas em um processo deliberativo. Por exemplo, a colocação, por qualquer membro, de uma nova alternativa entre as alternativas disponíveis ( $4^{\mathrm{a}}$ condição) não só é factível como faz parte do modus operandi do processo de deliberação.

A necessidade de todos os indivíduos possuírem informações idênticas sobre as alternativas $\left(5^{\text {a }}\right.$ condição $)$ também é mais bem atendida nesse espaço, uma vez que as argumentações devem ser fundamentadas, muitas das vezes, com a revelação de informações antes privativas. Além disso, o caráter setorial dos conselhos contribui para a especialização das informações necessárias à tomada de decisão devido à redução do escopo em análise.

se daria por meio de uma ação comunicativa, pela mera "influência" nas decisões governamentais, legislativas ou do executivo. O que não é o caso dos conselhos, dado seu caráter estatal e institucionalizado.

${ }^{5}$ Condição que se refere à capacidade cognitiva limitada para receber, armazenar, recuperar e processar informação (WILLIAMSON, 1996, p. 377). 
A adoção das alternativas vencedoras em substituição às perdedoras, bem como a redução do problema do "agente principal" entre a burocracia e os representantes $\left(6^{\mathrm{a}}\right.$ e $7^{\mathrm{a}}$ condições, respectivamente) também são mais bem atendidas nesse espaço, dado o caráter deliberativo e a proximidade entre representantes, burocracia e os resultados objetivos da política pública escolhida, o que favorece o controle sobre o governo. Quanto ao aspecto das decisões tomadas durante o mandato ( $8^{\mathrm{a}}$ condição), cabe lembrar que os conselhos são órgãos perenes, cuja frequência de reunião e deliberação deve ser determinada por regras. Assim, há de se supor que, ainda que potencialmente, as decisões importantes e pertinentes são tomadas após discussão nesse fórum, sempre que necessário.

Além disso, o processo deliberativo também permite a manifestação da intensidade das preferências sobre determinada política pública, superando as limitações de atribuir pesos iguais a intensidades diferentes, característica de um processo de simples agregação.

Ou seja, por meio da deliberação nos conselhos é possível, por um lado, aprimorar o método democrático de tomada de decisão, baseado nas considerações sobre melhor distribuição da informação e o aprimoramento da capacidade de interpretação e julgamento destas por meio da argumentação. Por outro lado, essa deliberação democrática pode levar a melhores resultados devido à maior facilidade de obter uma concertação de interesses, que não tem necessariamente a pretensão de atingir um consenso ou revelar um improvável "bem comum", mas que qualifica e viabiliza a tomada de decisões coletivas.

\section{Os conselhos e o potencial de controle e responsabilização}

Contudo, além de constituir espaço democrático, aos conselhos gestores também está colocada uma questão de eficiência. Esse novo papel atribuído à sociedade, qual seja, o de contribuir para uma maior eficiência no uso dos recursos públicos, principalmente pelo exercício de controle sobre os governantes, está presente nos movimentos de reforma do Estado das últimas duas décadas, particularmente em um contexto onde a configuração tradicional dos governos, principalmente relativa à sua função executiva, cede espaço ao conceito mais amplo de "governança". Fundamentalmente, esse conceito reconhece a existência e, sobretudo, a conveniência da participação ativa das estruturas de poder localizadas fora das instituições formais de governo, para o desenvolvimento sustentável dos países. É dessa forma que novos papéis são atribuídos à sociedade civil, ao setor privado, aos outros níveis de governo ou às organizações não governamentais, entre outros agentes (UN-HABITAT, 2002).

É nesse contexto, portanto, de deslocamento da responsabilidade pela gestão da coisa pública, antes exclusiva dos governos, para os atores de uma boa governança, que surgem novas formas de controle sobre os governos, além dos tradicionais controle parlamentar e judicial. Algumas delas, conforme estudo do CLAD (2000), são o controle por concorrência administrada, o controle por resultados e o controle social. O primeiro constitui basicamente uma forma de controle típico de mercado, baseado no estabelecimento ou no acirramento administrado da competição entre prestadores de serviços públicos, estatais ou não, com vistas a "quebrar" os monopólios na prestação dos serviços e propiciar ao usuário/cidadão a possibilidade de "saída", o que levaria a pressões permanentes por maior eficiência e eficácia na prestação do serviço. Por sua vez, o controle por resultados consiste no estabelecimento de metas e resultados a ser alcançados, sob os quais as organizações privadas ou públicas, financiadas com recursos públicos, ficam comprometidas. A avaliação retrospectiva dos resultados obtidos torna-se a condição para a renovação dos compromissos ou sua suspensão. Esses controles inserem-se na agenda de reforma do Estado sob a perspectiva de uma mudança da lógica burocrática, onde há um excessivo apego aos procedimentos e às regras (meios), para uma lógica gerencial, com ênfase nos resultados.

Já o controle social refere-se, aqui, a um controle ascendente, associado à responsividade e à responsabilização do governo em uma relação constante e não eleitoral com a sociedade. Isso implica para a sociedade, como nas eleições, o direito de exigir a prestação de contas no uso dos recursos, influenciar ou 
decidir sobre escolha das políticas públicas, fiscalizar o cumprimento de suas deliberações e sancionar, entre outras prerrogativas. Tal controle pode ser empreendido de forma direta ou por meio de instâncias de representação distintas da representação parlamentar, como os conselhos gestores deliberativos ${ }^{6}$.

Dessa forma, no que tange à eficiência das políticas públicas, podemos identificar dois objetivos principais dos conselhos gestores de políticas públicas: a identificação, captação e ponderação constante das preferências da sociedade, com vistas à formulação de políticas públicas e o controle social sobre estas, incluindo a responsividade às demandas da sociedade e a responsabilização dos governantes. $O$ primeiro objetivo, viabilizar a manifestação, a identificação e a captação de preferências da sociedade, considerando seus aspectos de intensidade variada e de variabilidade no tempo, permitindo a formulação de políticas públicas compatíveis, constitui, fundamentalmente, uma questão pertinente à necessidade de maior eficiência econômica e social na alocação dos recursos públicos. Ou seja, em um contexto de boa governança, a abertura de um espaço de manifestação constante da sociedade permitiria ao Estado identificar as necessidades prioritárias e, ainda, receber aporte de conhecimento quanto à melhor forma de abordá-las. Esse objetivo, que não recebe neste estudo uma atenção específica, refere-se fundamentalmente às questões relativas à representatividade dos conselheiros ou das preferências captadas e também à eficiência do processo deliberativo envolvido na formulação das políticas e no processo de tomada de decisão, assuntos já mencionados.

No entanto, e assim passamos ao segundo objetivo, o seguimento ou cumprimento das políticas públicas formuladas pelo conselho, a partir das preferências e deliberações, passa a ser uma questão de controle. $\mathrm{Ou}$ seja, a responsividade a essas preferências manifestadas depende de o conselho conseguir se tornar, de fato, uma instância de controle social eficiente sobre o governo.

Entretanto, a que, precisamente, refere-se esse controle? Da teoria administrativa, o controle, ao lado do planejamento, da organização e da direção, é uma das quatro funções clássicas da administração (URDAN, 1997). Assim, dos compêndios da teoria, podemos extrair de Fayol (1976, p. 143) a seguinte definição:

O controle consiste em verificar se tudo está correndo em conformidade com o plano adotado, as instruções emitidas e os princípios estabelecidos. Seu objetivo é apontar as faltas e os erros para que se possa retificá-los e evitar a sua reincidência. Aplica-se a tudo: coisas, pessoas e atos.

Por sua vez, por "accountability" entendo a "suscetibilidade ao controle", particularmente ao controle sobre os resultados (sobre as "coisas"), executado por mecanismos objetivos e exteriores ao responsável. Essa definição reforça a perspectiva do "accountability" estar associado exclusivamente a uma imposição externa ao indivíduo, abandonando qualquer conotação moral relativa à introjeção de valores públicos pelo agente. Assim, o processo de "accountability" envolve, essencialmente, quatro eventos sequenciais: a apuração dos resultados; seu julgamento como adequados ou inadequados ao previsto; a identificação dos responsáveis; e sua sanção ${ }^{7}$.

\footnotetext{
${ }^{6}$ O conceito clássico de "controle social" provém da sociologia e significa o "conjunto de meios de intervenção, quer positivos ou negativos, acionados por cada sociedade ou grupo social a fim de induzir os próprios membros a se conformar às normas que a caracterizam" (GARELLI, 1983, p. 285). Ou seja, é um controle exercido pela sociedade sobre seus membros individualmente e, em decorrência, sobre si. Também na política, o uso do termo não é recente, apesar das diferenças extremas entre o conceito antigo e 0 atual. No tocante ao Estado, o conceito antigo de controle social se referia, após a crise da ideologia liberal, às intervenções estatais na sociedade, com vistas a promover uma situação de segurança social.

${ }^{7}$ Cabe observar que, no caso do conceito de "accountability", talvez fosse mais correto falar de "controle a partir dos resultados" ao invés de "controle sobre os resultados", uma vez que este último sugere a possibilidade de influenciar os resultados preventivamente.
} 
Quanto ao conceito de responsabilização, este engloba e vai além do conceito de "accountability" por duas razões. Primeiro, porque também se aplica aos meios e não apenas aos resultados, em uma espécie de "accountability ex-ante", ou preventiva. Constitui, assim, uma garantia prévia do comportamento responsivo, ou seja, uma forma externa de assegurar que as políticas adotadas correspondam àquelas escolhidas e que os comportamentos dos atores correspondam ao esperado. Remetendo à definição de Fayol (1976), seria o controle preventivo aplicado também às pessoas e aos atos; é anterior, portanto, aos resultados.

Em segundo lugar, e aqui há uma extrapolação do conceito de controle de Fayol (1976), há uma dimensão moral na responsabilização, ausente no conceito de "accountability" (CAMPOS, 1990; CUNILL GRAU, 2000). Ela é referente à possibilidade do agente comportar-se de acordo com valores republicanos e democráticos devido à introjeção desses valores e não devido à imposição externa. Ou seja, seria uma responsividade "self-enforced" em contraponto à responsividade assegurada por mecanismos externos de responsabilização; representaria a diferença entre "responsabilizar-se por" e "ser responsabilizado por".

Portanto, o conceito de controle social aqui utilizado, além da responsividade, abrange o conceito de responsabilização em todas as suas dimensões. Ou seja, significa o controle sobre os meios ou políticas, sobre as pessoas ou agentes e a partir dos resultados, valendo-se tanto de imposições externas como de constrangimentos subjetivos.

A questão que enfim se coloca é se os conselhos municipais gestores de políticas públicas constituem potencial agente de um eficiente controle social. Inicialmente, ao lado das questões de assimetria de informação, capacidade cognitiva e disponibilidade de instrumentos de sanção, uma importante problemática em relação ao controle refere-se às considerações sobre a cogestão, isto é, sobre a participação constitutiva da sociedade no conselho e em suas deliberações, o que os impediria de configurar sujeito eficaz e imparcial de controle sobre o Estado.

Sobre esse ponto, Cunill Grau (2000, p. 280), por exemplo, é taxativa: “A cogestão é inconciliável com o controle". Para ela, a eficácia do controle é diretamente dependente da independência e autonomia que os atores do controle social mantêm em relação ao Estado. Sua justificativa para tal afirmação, no entanto, não se baseia em uma possível incompatibilidade técnica acerca da coexistência das funções de deliberação e controle em um mesmo órgão, mas, sim, em evidências empíricas de que a institucionalização da participação cidadã na América Latina tem favorecido determinadas categorias de interesses particulares, bem como direcionado o conteúdo a ser submetido ao controle, buscando apenas a colaboração funcional da sociedade no exercício da política e não a influência e o controle sobre ela (CUNILL GRAU, 1998, p. 153). $\mathrm{Ou}$ seja, acreditamos que sua restrição decorra dos problemas do desenho institucional relativo à representação da sociedade, ao conteúdo em questão e ao modus operandi das instâncias de participação observadas, e não de uma impossibilidade teórica de consubstanciar, em um mesmo órgão, as funções diretivas e de controle.

Outra referência importante à eventual necessidade de separação entre controlado e controlador é a teoria de separação de poderes de Montesquieu, curiosamente inspirada no modelo parlamentarista inglês. Segundo Albuquerque (1998, p. 120), no entanto, tal separação refere-se a um problema político e não a um problema jurídico-administrativo de organização de funções. Isto é, a teoria da separação de poderes refere-se, originalmente, às diferentes bases sociais que dão origem ao poder e não às diferentes funções que os poderes venham a assumir. O objetivo é evitar a tirania de determinada fração social sobre as demais, permitindo que tenham poderes equivalentes; não se trata, portanto, de estabelecer que uma função deva ser exercida exclusivamente por um ou outro poder.

Dessa forma, não acredito na impossibilidade funcional do conselho gestor se encarregar, de fato, da gestão completa da política pública, o que, como já definido, envolve desde a formulação e o planejamento da política pública até a avaliação e controle de seus resultados. No entanto, cabe reconhecer que ao menos uma etapa do ciclo de gestão pode ficar parcialmente prejudicada: o estabelecimento de ações corretivas e preventivas mais drásticas aos comportamentos desviantes. Isto é, a utilização de mecanismos mais rigorosos de sanção pelos conselheiros pode ser limitada, no âmbito dos conselhos, por pelo menos quatro motivos: 
sua inexistência institucional; o fato dos conselheiros da sociedade civil serem corresponsáveis pelos desvios; a paralisia que pode trazer ao governo; e o efeito negativo que isso implicaria na relação cooperativa do conselho.

No caso dos instrumentos de sanção, como coloca Cunill Grau (2000, p. 79), é indispensável que a sociedade disponha de recursos coercitivos respaldados legalmente que possam aumentar a eficácia das sanções simbólicas eventualmente disponíveis. Isso porque estas não têm efeitos mandatórios, ficando sua eficácia dependente da capacidade de gerar escândalos ou protestos que cheguem à grande mídia. Entretanto, isso é uma prerrogativa definida pelo arcabouço institucional/legal. No caso específico do Brasil, os conselhos gestores não possuem esses mecanismos: "São órgãos com função de controle, contudo, não correicionais, à base da tentativa de anulação do poder político-administrativo” (MOREIRA, 2002, p. 20).

Entretanto, independentemente da disponibilidade dos instrumentos de sanção, outro ponto relevante que coloca em dúvida a viabilidade da sociedade civil constituir ator de controle social, por intermédio dos conselhos, é o fato dos conselheiros da sociedade civil participarem constitutivamente das deliberações do conselho. Ou seja, na hipótese do governo ser responsivo às decisões do conselho e as políticas então adotadas produzirem resultados não representativos, no sentido de representação de Pitkin (1967 citado em PRZEWORSKI, STOKES e MANIN, 1999, p. 2), ou seja, resultados que não levem ao melhor interesse público, a própria sociedade representada deveria sancionar a si própria ${ }^{8}$ ?

A terceira questão, que pode tornar tais mecanismos de sanção não recomendáveis, refere-se à ameaça que representa ao andamento da política. Como colocam March e Olsen (1995), excesso de "accountability" pode levar à procrastinação e excessiva consideração de possibilidades, reduzindo a assunção de riscos, tornando os decisores mais receosos dos erros que podem se tornar públicos, e estimulando-os a permanecerem em cursos de ação que aparentemente já falharam. Lembram que por trás do conceito de "accountability" encontra-se a presunção de liberdade do agente, sem a qual não faria sentido falar em controle (MARCH e OLSEN, 1995, p.146).

Finalmente, a quarta e mais importante razão para a não utilização de recursos externos e extremos de sanção no conselho, para punir atos graves de irresponsabilidade de um agente do governo, repousa sobre o fato de que, talvez, sua utilização não seja mesmo adequada às relações de confiança e cooperação que se espera que ocorram em uma gestão participativa. Ou seja, o caráter deliberativo do conselho e seu funcionamento continuado favorecem a interação "face a face", o compartilhamento de dificuldades e soluções, o conhecimento e a identificação com o outro, a promoção de respeito, confiança e empatia mútuos. Favorecem, portanto, condições para uma relação cooperativa ou de "soma positiva" que, estrategicamente, devem ser preservadas.

Além disso, como colocam March e Olsen (1989, p. 118), a visão de "accountability", baseada na imposição de sanções externas ao comportamento não responsivo, decorre da assunção que o comportamento dos agentes públicos segue uma agenda privada e maximizadora de sua utilidade. Assim, a solução encontrada é estabelecer incentivos de tal forma que os agentes, agindo racionalmente, em seu próprio interesse, também agiriam no sentido do interesse público.

No entanto, em contraponto a essa visão, March e Olsen (1989, p. 118-119) defendem o que denominam uma "concepção integradora" do processo político, na qual o comportamento individual segue outro padrão, baseado em história, cultura, identidades, obrigações morais e razão. O comportamento não responsivo do

\footnotetext{
${ }^{8}$ Essa questão é pertinente, caso o governo seja responsivo ao conselho. No entanto, como lembra Daniel (1988, p. 35), o governo local não é monolítico, o que abre espaços para uma não responsividade da fração executora do governo em relação à fração do governo representada no conselho. Nesse caso, outra relação agente/principal passa a ser o foco, tornando-se provavelmente um problema hierárquico.
} 
agente seria, então, um problema de integridade profissional, de tal modo que a solução passaria pela sua socialização em princípios e valores éticos e coletivos. Dessa concepção, o importante, aqui, é que a característica deliberativa dos conselhos pode favorecer tal socialização, e, portanto, o controle social, uma vez que, em compensação à ausência de mecanismos externos de sanção, promoveria a introjeção de valores públicos pelo agente.

Essas reflexões, sobre a indisponibilidade e a inadequação estratégica dos instrumentos de sanção e sobre a cogestão da sociedade civil com o Estado, possibilitam algumas conclusões quanto à amplitude e à profundidade possíveis do controle social pelos conselhos gestores. Basicamente, elas levam à constatação de que os conselhos têm condições para agir corretivamente sobre as políticas e a partir dos resultados; mas não têm capacidade nem incentivos para sancionar, com rigor, os agentes do governo ou os conselheiros. Resgatando a definição de Fayol (1976) sobre controle, as ações corretivas profundas somente ocorreriam quanto aos desvios nos procedimentos (atos) e nos resultados (coisas), mas não quanto aos desvios de comportamentos (pessoas).

Apesar disso, refletindo sobre esses âmbitos possíveis de incidência de controle por parte dos conselhos, seja sobre a política em si, seja a partir dos resultados, e ressalvados os potenciais problemas de representação já tratados, é possível afirmar que o processo de deliberação, característico dos conselhos, favorece duas condições essenciais à responsividade às preferências e à responsabilização do governo ou, mais propriamente, à ação corretiva sobre os rumos da política: a redução da assimetria de informações e o aumento da capacidade cognitiva para sua interpretação e julgamento. Primeiramente, a interlocução argumentada com os conselheiros da sociedade civil permite à burocracia do Estado precisar e apurar melhor as preferências sinalizadas, o que favorece a aderência destas às políticas adotadas.

Quanto à responsabilização, a deliberação entre os representantes do governo e da sociedade civil e o "sentir na pele" os resultados da política, favorecem, como já discutido, a uniformização de informações e o julgamento argumentado delas, viabilizando o fim uma maior coerência entre comportamentos, ações ou resultados e as ações corretivas, ainda que brandas, aplicadas aos desvios respectivos.

Em suma, o potencial de controle social a partir dos conselhos é tímido, se falarmos da prerrogativa de vigorosas sanções sobre os responsáveis, mas pode ser bastante promissor se tratarmos do controle sobre as dimensões técnica e administrativa da política pública em si e, também, do processo de socialização paulatina dos participantes do colegiado, agentes públicos e conselheiros da sociedade civil, em valores e princípios democráticos e republicanos.

\section{Conclusão}

As considerações teóricas apresentadas neste artigo revelam, com algumas ressalvas, que os conselhos gestores têm potencial para promover o aprofundamento da democracia na gestão das políticas públicas, particularmente por meio da mitigação das deficiências do sistema representativo e do método democrático de agregação e pelo fortalecimento de condições que viabilizam um processo deliberativo igualitário. Esse potencial, no entanto, encontra maiores possibilidades de realização no âmbito local, particularmente municipal, e em instâncias cujo escopo é setorial; o que, ainda assim, não os isenta de deparar-se com dúvidas em relação à legitimidade democrática das instituições participantes e à legitimidade "eleitoral" dos conselheiros da sociedade civil.

Para alcançar tal intuito há, obrigatoriamente, a necessidade de estabelecer arranjos institucionais que estimulem a ampliação da participação voluntária da população nessas instâncias de poder, zelem pela pluralidade e representatividade desses conselheiros e governem a relação de representação entre conselheiros e sociedade civil. A efetividade de tais arranjos aumenta à medida que logram distribuir a informação, especializar o escopo em discussão e garantir a manifestação livre e argumentada dos 
representantes. Cabe ressaltar, ainda, que tais arranjos são crescentemente complexos, em termos de alcance de efetividade na obtenção da representatividade democrática e da eficiência dos conselhos, quanto mais abrangente em escopo e em população representada for a instância.

Quanto à questão de eficiência colocada aos conselhos, destaca-se que seu caráter deliberativo e seu funcionamento continuado favorecem algumas condições necessárias a uma interação cooperativa ou de "soma positiva". Além disso, favorecem o compartilhamento de valores entre os participantes ou, segundo March e Olsen (1989, p. 118-119), a socialização dos agentes públicos em valores e princípios democráticos e republicanos. Essa questão é particularmente importante, porque resgata uma dimensão esquecida, que se refere ao papel, à identidade e à integridade profissional do agente público; contrapõe, portanto, a visão individualista predominante que supõe que o agente segue um comportamento egoísta e maximizador de utilidade, de tal forma que o único controle possível repousa na aplicação de incentivos externos que promovam a convergência entre os interesses públicos e a agenda privada do agente.

Entretanto, isso também significa que fortes antagonismos devem ser estrategicamente evitados no interior do conselho, de tal forma que, em termos de responsabilização dos governantes, considerarmos viável apenas a possibilidade de "sanções" subjetivas, visando a obter uma espécie de responsividade "self-enforced" decorrente da introjeção de valores e princípios públicos pelo agente. Apesar disso, os conselhos têm grande potencial para exercer um controle mais rigoroso e concreto sobre a política pública em si e sobre seus resultados, devido à redução da assimetria de informações e o aumento da capacidade cognitiva para sua interpretação e julgamento, condições favorecidas pelo processo de deliberação. Mais uma vez, no entanto, grande ênfase deve ser dada ao desenho institucional, como forma de garantir os instrumentos que viabilizam a colocação da agenda do conselho nos planos e orçamentos públicos e o monitoramento de sua execução, em um ambiente de argumentação livre entre iguais.

Finalmente, atenção especial deve ser dada ao fomento de instâncias de participação cujo escopo singular é o controle da representação.

\section{Referências}

ALBUQUERQUE, J. A. G. Montesquieu: sociedade e poder. In: WEFFORT, F. C. (Org.). Os clássicos da política. São Paulo: Ática, 1998. v. 1. 11-186 p.

AVRITZER, L. Teoria democrática, esfera pública e participação local. Sociologias, v. 1, n. 2, p. 18-43, 1999.

CAMPOS, A. M. C. Accountability: quando poderemos traduzi-la para o português? Rev. Adm. Pública, v. 24, n. 2, p. 30-50, 1990.

CARVALHO, M. C. A. A. Participação social no Brasil hoje. Paper. São Paulo: Instituto Pólis, 1998.

CENTRO LATINOAMERICANO DE ADMINISTRACIÓN PARA EL DESARROLLO - CLAD. La responsabilización ('accountability') en la nueva gestión pública latinoamericana. In: CENTRO LATINOAMERICANO DE ADMINISTRACIÓN PARA EL DESARROLLO - CLAD. La responsabilización en la nueva gestión pública latinoamericana. Caracas: CLAD, 2000. 77-76 p.

COHEN, J. Democracy and liberty. In: ELSTER, J. (Org.). Deliberative democracy. Cambridge: Cambridge University Press, 1998. 185-231 p.

CUNILL GRAU, N. Repensando o público através da sociedade: novas formas de gestão pública e representação social. Brasília, DF: ENAP, 1998.

CUNILL GRAU, N. Responsabilización por el control social. In: CENTRO LATINOAMERICANO DE ADMINISTRACIÓN PARA EL DESARROLLO - CLAD. La responsabilización en la nueva gestión pública latinoamericana. Caracas: CLAD, 2000. 269-328 p. 
DAHL, R. A. Um prefácio à teoria democrática. Rio de Janeiro: Jorge Zahar, 1989. 70-74 p.

DAHL, R. A. Poliarquia: participação e oposição. São Paulo: Edusp, 1997.

DANIEL, C. Poder local no Brasil urbano. Espaço \& Debates, n. 24, 1988.

ELSTER, J. Introduction. In: ELSTER, J. (Org.). Deliberative democracy. Cambridge: Cambridge University Press, 1998. 1-280 p.

FAYOL, H. Administração industrial e geral. São Paulo: Atlas, 1976.

FEARON, J. D. Deliberation as discussion. In: ELSTER, J. (Org.). Deliberative democracy. Cambridge: Cambridge University Press, 1998. 44-68 p.

GAMBETTA, D. "Claro!”: An essay on discursive machismo. In: ELSTER, J. (Org.). Deliberative democracy. Cambridge: Cambridge University Press, 1998. 19-43 p.

GARELLI, F. Controle social. In: BOBBIO, N.; MATTEUCCI, N.; PASQUINO, G. (Org.). Dicionário de política. 12. ed. Brasília, DF: Ed. UnB, 1999. 283-285 p.

GOHN, M. G. Conselhos gestores e participação sociopolítica. São Paulo: Cortez, 2001.

GOMES, E. G. M. Conselhos gestores de políticas públicas: democracia, controle social e instituições. Dissertação (Mestrado em Administração Pública e Governo) - Escola de Administração de Empresas de São Paulo, Fundação Getulio Vargas, São Paulo, 2003.

LANE, F. C. Profits from power: readings in protection rent and violence controlling enterprises. Albany: State University of New York Press, 1979.

MARCH, J.; OLSEN, J. P. Rediscovering institutions: the organizational basis of politics. New York: The Free Press, 1989.

MARCH, J.; OLSEN, J. Democratic governance. New York: The Free Press, 1995.

MOREIRA, M. T. V. Instância deliberativa das políticas de cunho social: contorno jurídico dos conselhos. Informativo Cepam, v. 1, n. 3, p. 20-26, 2002.

PITKIN, H. F. The concept of representation. Berkeley: University of California Press, 1967.

PRZEWORSKI, A. Democracia e mercado: reformas políticas e econômicas no Leste Europeu e na América Latina. Rio de janeiro: Relume-Dumará, 1994.

PRZEWORSKI, A. Sobre o desenho do Estado: uma perspectiva agent x principal. In SPINK, P.; BRESSER PEREIRA, L. C. (Orgs.). Reforma do Estado e administração pública gerencial. 2. ed. Rio de Janeiro: Ed. FGV, 1998. 39-76 p.

PRZEWORSKI, A.; STOKES, S. C.; MANIN, B. Democracy, accountability and representation. Cambridge: Cambridge University Press, 1999.

TEIXEIRA, E. C. Efetividade e eficácia dos conselhos. In: CARVALHO, M. C. A.; TEIXEIRA, A. C. C. (Orgs.). Conselhos gestores de políticas públicas. São Paulo: Instituto Pólis, 2000. 92-96 p.

UNITED NATIONS HUMAN SETTLEMENTS PROGRAMME - UN-HABITAT. Global campaign on urban governance: urban governance index - discussion note. 2002.

URBINATI, N. Rhetoric and representation: the politics of advocacy. Chicago, IL: University of Chicago Press, 1999.

URDAN, A. T. Curso de formação gerencial básica: planejamento, organização, direção e controle. Belo Horizonte: Centro de Extensão da UFMG, 1997.

WILLIAMSON, O. E. The mechanisms of governance. New York: Oxford University Press, 1996. 